\title{
CENTRAL AXIS ESTIMATION FOR ANCIENT CHINESE PAGODAS BASED ON GEOMETRIC MODELLING AND UAV-BASED PHOTOGRAMMETRY
}

\author{
Ting On Chan ${ }^{1,2, *}$, Linyuan Xia ${ }^{1}$, Jiahui Tang ${ }^{3}$, Mengwei Liu ${ }^{3}$, Wei Lang ${ }^{1,2}$, Tingting Chen ${ }^{1,2}$, Hang Xiao ${ }^{1}$ \\ ${ }^{1}$ Guangdong Provincial Key Laboratory of Urbanization and Geo-simulation, School of Geography and Planning, Sun Yat-sen \\ University, Guangzhou, China - chantingon@ mail.sysu.edu.cn; \\ ${ }^{2}$ China Regional Coordinated Development and Rural Construction Institute, Sun Yat-sen University, Guangzhou 510275, China \\ ${ }^{3}$ Guangzhou SenseWing Robot Technologies Co., Ltd., Guangzhou, China
}

\section{Commission II}

KEY WORDS: Cultural Heritage, Pagoda, Geometric Model, UAV, Symmetry

\begin{abstract}
:
Pagodas are common historical structures in China and some other Asian countries. Symmetries of the pagodas play an important role on cultural and structural aspects. In this paper, we proposed a method estimating the central axis of a typical ancient pagoda in China for examination of its symmetry. We developed a novel geometric model to fit to the point cloud of the pagoda obtained from photogrammetric reconstruction based on UAV imagery. More specifically, we developed a novel geometric model possessing 16 parameters to fit to the point cloud of different parts of the pagodas simultaneously to estimate a central axis for the symmetry. The results show that the proposed model is superior to the conventional cylindrical models for the central axis estimation. More importantly, the estimated parameters are in realistic ranges, as well as the reconstructed central axis and the sextant number are well visualized, so the symmetry of the pagodas can be readily analysed.
\end{abstract}

\section{INTRODUCTION}

Oriental ancient architecture has attracted a great deal of attention from those who investigate cultural heritages and modern architectural design. Many components and even the entire bodies of those architectural structures are symmetric. The symmetry can be found on many different types of structures such as the gateways (toranas), pagodas, and pavilions. In China, the earliest symmetrical structure can be found from architecture built in Shang dynasty (1046 BC). Many other Chinese ancient architectural structures built during the last 500 years were also found to possess many symmetries.

To examine the degree of symmetry, a central axis should be accurately known. Xue et al. (2018) proposed a slice-based method to estimate the position and orientation of the central axis for the symmetry. They adopted the derivative-free optimization to accelerate the computation in which each slice of the point cloud is analysed to estimate a rough axis position. $\mathrm{Li}$ et al. (2018) used the ellipse and plane fitting techniques to compute the central axis position of point clouds of some objects based on a voting algorithm. This method is accurate, but it is not very computationally efficient. Cheng et al. (2018) developed a set of point cloud registration method based on the symmetry of architectural structures. They use sine function fitting to extract the symmetrical parameters computed from slices of the point clouds. The position and orientation of the central axis can be then estimated from each slice.

Researchers from the field of the computer vision and graphics, have put much emphasis on detecting symmetry over the past three decades. For examples, Bartalucci et al. (2018) presented a thorough review of the symmetry analysis on biomedical imaging systems. Jiang et al. (2013) proposed a skeleton-based method to detect symmetry from 3D point clouds. This method primarily extracted the symmetrical nodes from the mesh and then used a voting algorithm to extract the symmetry. Musuvathy et al. (2011) used the Eikonal equation to estimate

* Corresponding author parameters of a 3D volume based on the B-spline surface which embraced the entire volume. Berner et al. (2009) proposed a method which could detect mild deviation from the symmetry of an object by registering different topographical planes. Combès et al. (2008) simplified the conventional Iterative Closest Points (ICP) algorithm to estimates a plane for the reflection symmetry of the point cloud of a $3 \mathrm{D}$ object.

In the paper, we developed a model-based method to estimate the central axis of a typical Chinese pagoda for investigation of the pagoda's symmetry. Most of the ancient Chinese pagodas are polygonal structures (Figure 1). The hexagonal and the octagonal pagodas are the most popular. They usually consist of multilayers of polygonal prism or pyramid, including eaves.

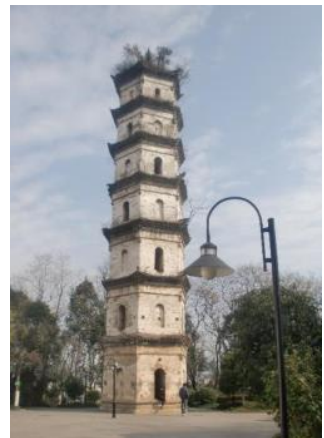

(a) hexagonal

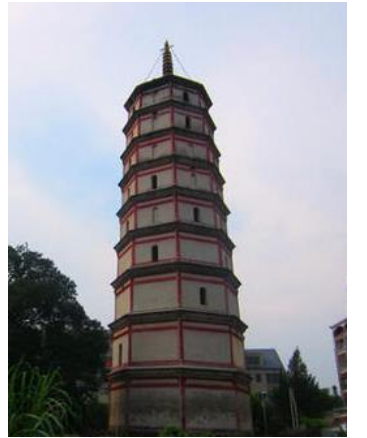

(b) octagonal
Figure 1. Typical ancient Chinese pagodas

A novel geometric model is proposed for the pagoda to fit to the point cloud obtained from photogrammetric reconstruction based on unmanned aerial vehicle (UAV) imagery. The Wenfeng Pagoda in Southern China is studied as example. The Wenfeng Pagoda is a 300 years old architecture, having three floors. The model consists of multiple components and are incorporated into a single adjustment with the Gauss-Helmert model to estimate the parameters of the central axis. The axis 
parameters basically which share the same centre and the inclination angles with the pagoda model.

\section{METHOD}

\subsection{Pagoda Segmentation}

Similar to a method detecting a pillar (Luo and Wang, 2008), segmentation of the entire pagoda is performed based on a fslice-based method which decomposes the whole point clouds (Figure 2) into multiple slice using a small height window (e.g. $5 \mathrm{~cm}$ ) to create multiple cross-sections (Figure 3). Then, circle fitting is employed to check the similarity between the point clouds and a circle with a certain radius. If a point belongs to those cross-sections with relatively smaller fitting residuals and similar radii (mode of all the radii), it is segmented as one of the points of the pagoda point cloud.

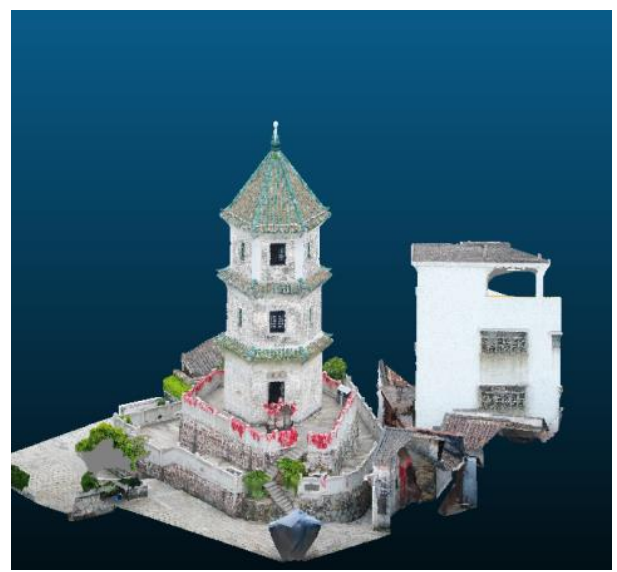

Figure 2. Point clouds reconstructed from UAV photogrammetry for the Wenfeng pagoda located in Guangdong Province, China

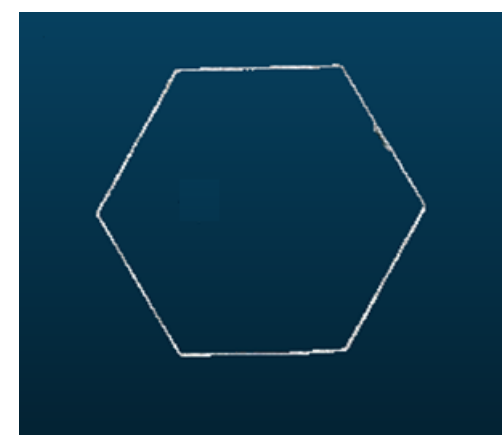

Figure 3. Cross-section of the point cloud (belongs to the pagoda)

\subsection{Proposed Model for Polygonal Pagodas}

The Wenfeng Pagoda consists of three floors which are hexagonal prisms with different radii. The hexagonal prism can be modelled with Equation 1 by setting $n=6$ (Chan et al., 2016), the model parameters were shown in Figure 4. They include the center of the prism $\left(X_{\mathrm{c}}, Y_{\mathrm{c}}\right)$, the rotations about the $\mathrm{X}$-axis $(\Omega)$, Y-axis $(\Phi)$ and $\mathrm{Z}$-axis $(\Psi)$ for the prism, the polygonal radius $\left(R_{0}\right)$ and the gradient factor $(k)$. When $k=0$, the model is for a prism, otherwise, it is for a pyramid. $f(\vec{x}, \vec{l})=\left[\left(R_{0}-k Z^{\prime}\right)-X^{\prime}\right] \tan \left(\left(1-\frac{2}{n}\right) \cdot 90^{\circ}\right)-Y^{\prime}=0$

where

$\left(\begin{array}{c}X^{\prime} \\ Y^{\prime} \\ Z^{\prime}\end{array}\right)=\mathbf{R}_{3}\left((q-1) \cdot \frac{360^{\circ}}{n}+\Psi\right) \mathbf{R}_{2}(\Phi) \mathbf{R}_{1}(\Omega)\left(\begin{array}{c}X-X_{\mathrm{c}} \\ Y-Y_{\mathrm{c}} \\ \mathrm{Z}\end{array}\right)$

and $n$ is the number of sides for the polygon. $q$ is a number indicating which sector a point belongs to (Figure 5), in the case of the hexagonal model, it is defined as the sextant number. It is computed as

$$
q=\left\lceil\frac{\theta n}{360^{\circ}}\right\rceil
$$

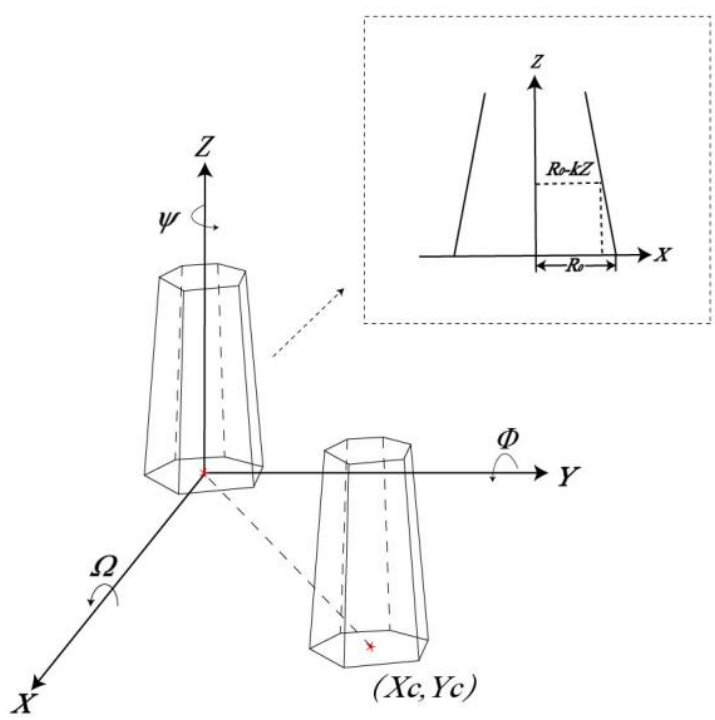

Figure 4 . The parameters of the hexagonal prism/pyramid model

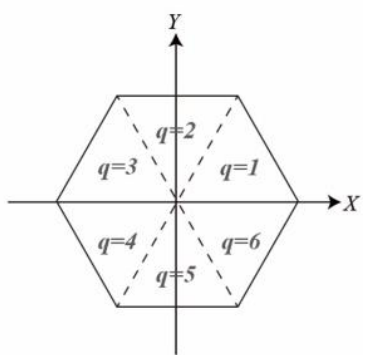

Figure 5. The sextant number $(q)$ for the model

A typical ancient Chinese pagoda is composed of multiple layers of polygonal structures (main body and eaves). The main body is usually a polygonal prism, composes a floor of the pagoda. Between two main body floors, there is usually an eave which can be modelled with a polygonal pyramid. It is worth noting that in between the eaves, the prism diameter is not consistent (usually the diameter decreases for higher floor) for most pagodas. This is illustrated in Figure 6 that the diameter or the radius of the floor decreases at higher floor (the space between the red line and the prism at the floor increases for higher floor). Therefore, the same geometric models augmented with different radii are used for the pagodas. 


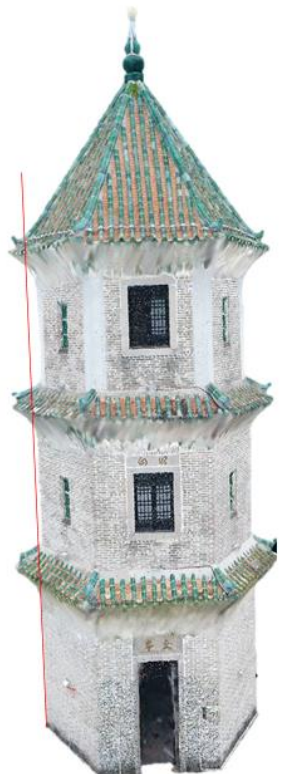

Figure 6. Diameter or the radius of the floor decreases at higher floor (the space between the red line and the prism at the floor increases for higher floor).

Despite how many layers a pagoda has, a unique central axis (its position and orientation) should be computed for the entire pagoda in order to study its symmetry. As a result, a geometric model which consists of multiple polygonal prism/pyramid is proposed for the pagoda. The model parameters for a hexagonal pagoda consisting three main bodies, three eaves, and one top pyramid are shown in Figure 7. This is an example of a 3-floor pagoda (as for Wenfeng Pagoda). The model can be readily modified to suit pagoda with different floors. They include the center of the pagoda $\left(X_{\mathrm{c}}, Y_{\mathrm{c}}\right)$, the rotations about the $\mathrm{X}$-axis $(\Omega)$, Y-axis $(\Phi)$ and $\mathrm{Z}$-axis $(\Psi)$, and a set of radius $\left(R_{\mathrm{i}}\right)$ and the gradient factor $\left(k_{i}\right)$ for each layer.

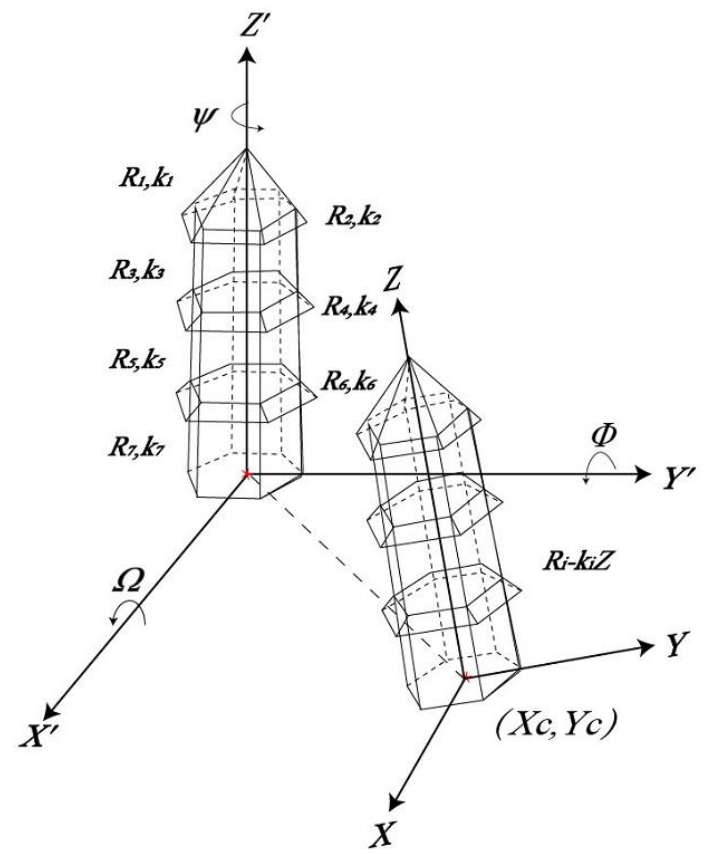

Figure 7. The parameters of the proposed polygonal pagoda model
To estimate the central axis, the Gauss-Helmert adjustment model (Förstner and Wrobel, 2004) is employed. The linearized adjustment model can be expressed as

$$
\mathbf{A} \hat{\delta}+\mathbf{B} \hat{v}+w=0
$$

where $\hat{\delta}$ is the correction vector for the parameters; $\mathbf{A}$ is the design matrix of partial derivatives of a set of functional models with respect to the model parameters; $\mathbf{B}$ is the design matrix of partial derivatives of the functional model with respect to the pagoda observations; $\hat{v}$ is the vector of residuals; and $w$ is the correction vector. $\hat{\delta}$ can be further broken down into two correction vectors storing the aforementioned model parameters:

$$
\overrightarrow{\delta_{\mathrm{p}}}=\left[\begin{array}{lllll}
x_{c} & y_{c} & \Omega & \Phi & \psi
\end{array}\right]^{\mathrm{T}}
$$

and

$$
\overrightarrow{\delta_{\mathrm{t}}}=\left[\begin{array}{lllllllllll}
k_{1} & R_{1} & k_{2} & R_{2} & R_{3} & k_{4} & R_{4} & R_{5} & k_{6} & R_{6} & R_{7}
\end{array}\right]^{\mathrm{T}}
$$

Therefore, Equation (4) can be further expanded as

$\left[\begin{array}{cc}\mathbf{A}_{\mathrm{p}}^{\mathrm{T}}\left(\mathbf{B P}^{-1} \mathbf{B}^{\mathrm{T}}\right)^{-1} \mathbf{A}_{\mathrm{P}} & \mathbf{A}_{\mathrm{pt}}^{\mathrm{T}}\left(\mathbf{B}_{\mathrm{t}} \mathbf{P}_{\mathrm{t}}^{-1} \mathbf{B}_{\mathrm{t}}^{\mathrm{T}}\right)^{-1} \mathbf{A}_{\mathrm{t}} \\ \mathbf{A}_{\mathrm{t}}^{\mathrm{T}}\left(\mathbf{B}_{\mathrm{t}} \mathbf{P}_{\mathrm{t}}^{-1} \mathbf{B}_{\mathrm{t}}^{\mathrm{T}}\right)^{-1} \mathbf{A}_{\mathrm{tp}} & \mathbf{A}_{\mathrm{t}}^{\mathrm{T}}\left(\mathbf{B}_{\mathrm{t}} \mathbf{P}_{\mathrm{t}}^{-1} \mathbf{B}_{\mathrm{t}}^{\mathrm{T}}\right)^{-1} \mathbf{A}_{\mathrm{t}}\end{array}\right]\left[\begin{array}{c}\delta_{\mathrm{p}} \\ \delta_{\mathrm{t}}\end{array}\right]+\left[\begin{array}{c}\mathbf{A}_{\mathrm{p}}^{\mathrm{T}}\left(\mathbf{B P}^{-1} \mathbf{B}^{\mathrm{T}}\right)^{-1} w \\ \mathbf{A}_{\mathrm{t}}^{\mathrm{T}}\left(\mathbf{B}_{\mathrm{t}} \mathbf{P}_{\mathrm{t}}^{-1} \mathbf{B}_{\mathrm{t}}^{\mathrm{T}}\right)^{-1} w_{\mathrm{t}}\end{array}\right]=\left[\begin{array}{c}0 \\ 0\end{array}\right]$

where $\mathbf{P}$ is the weight matrix for all observations. The subscripts $\mathrm{p}$ and $\mathrm{t}$ stand for the central axis parameters and the size parameters, respectively.

\section{EXPERIMENT}

With the involvement of the Guangzhou SenseWing Robot Technologies Co., Ltd., a typical ancient Chinese pagoda, the Wenfeng Pagoda located in Zhongshan city of Guangdong Province, China, was captured using the camera embedded on a DJI Phantom 4 UAV in July, 2017. Approximately 100 images were obtained and used to reconstruct the $3 \mathrm{D}$ point clouds of the Wenfeng Pagoda using the Smart3D software with the camera calibration parameters estimated.

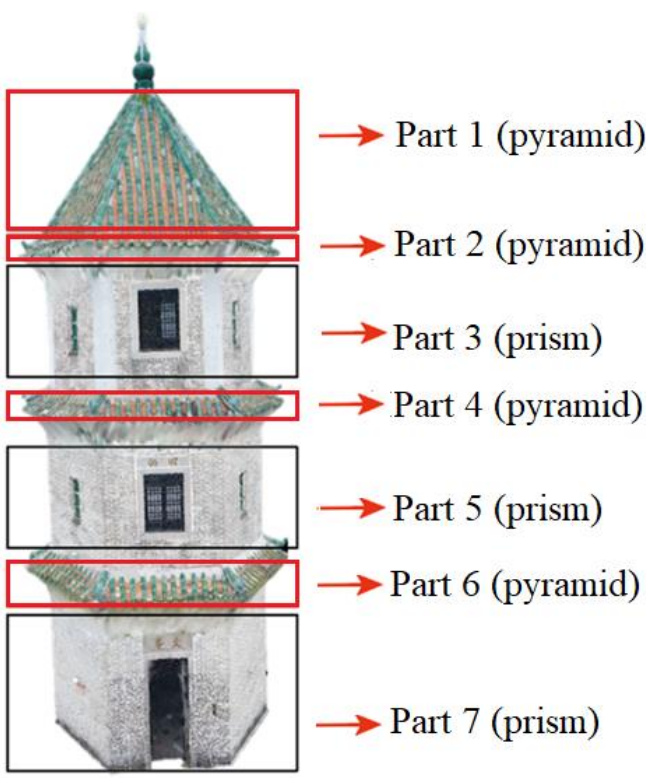

Figure 8. Seven parts of the Wenfeng pagodas and their nomenclature 
The pagoda and its seven components (defined as Parts 1-7 as shown in Figure 8) were extracted automatically using the Principal Component Analysis (PCA) algorithm (Demantké et al., 2011) and the pagoda height constraints along with some manual editing procedures. The $\mathrm{X}, \mathrm{Y}$, and $\mathrm{Z}$ coordinates of the pagoda were transformed to a local coordinate system and then fitted to the proposed adjustment model. The coordinates were also fitted to the conventional circular cylindrical/conic model (Chan et al., 2015) as control experiments. The initial values of the fitting could be obtained by using the circular cylindrical/conic models (Chan and Lichti, 2014).

\section{RESULTS}

\subsection{Comparison of the Model Fitting Results}

Different parts of the Wenfeng Pagoda point clouds were fitted to conventional cylindrical/conic model (Chan et al., 2015) and the hexagonal model individually. The estimated parameters and their standard deviations of Part 1 (the top), and Part 2 (the eave) and Part 3 (the main body) were tabulated in Tables 1, 2 and 3, respectively. It can be seen that the estimated parameters from the two fittings deviate significantly (translational $\sim 35$ $\mathrm{cm}$; angular $\sim 3 \mathrm{deg}$ ) Also, the standard deviations obtained from the hexagonal model fitting are much lower that from the circular cylindrical/conic models. This is because the pagoda is polygonal so the fitting to the circular cylindrical/conic models generated less accurate results.

Table 1. Estimated parameters of Part 1

\begin{tabular}{|c|c|c|c|c|c|}
\hline & \multicolumn{2}{|c|}{$\begin{array}{c}\text { Circular cone } \\
\text { fitting }\end{array}$} & & \multicolumn{2}{c|}{$\begin{array}{c}\text { Hexagonal pyramid } \\
\text { fitting }\end{array}$} \\
\hline & $\begin{array}{c}\text { Estimated } \\
\text { Value }\end{array}$ & $\begin{array}{c}\text { Standard } \\
\text { deviation }\end{array}$ & & $\begin{array}{c}\text { Estimated } \\
\text { Value }\end{array}$ & $\begin{array}{c}\text { Standard } \\
\text { deviation }\end{array}$ \\
\hline$X_{c}(\mathrm{~m})$ & -0.108 & $4.91 \mathrm{E}-05$ & $X_{c}(\mathrm{~m})$ & -0.108 & $2.89 \mathrm{E}-07$ \\
\hline$Y_{c}(\mathrm{~m})$ & -0.018 & $4.96 \mathrm{E}-05$ & $Y_{c}(\mathrm{~m})$ & -0.018 & $2.90 \mathrm{E}-07$ \\
\hline $\begin{array}{c}\Omega \\
(\mathrm{deg})\end{array}$ & -0.558 & $1.63 \mathrm{E}-03$ & $\begin{array}{c}\Omega \\
(\mathrm{deg})\end{array}$ & -0.448 & $9.94 \mathrm{E}-06$ \\
\hline $\begin{array}{c}\Phi \\
(\mathrm{deg})\end{array}$ & -1.803 & $1.62 \mathrm{E}-03$ & $\begin{array}{c}\Phi \\
(\mathrm{deg})\end{array}$ & -1.792 & $9.90 \mathrm{E}-06$ \\
\hline$k$ & 0.661 & $2.88 \mathrm{E}-05$ & $\begin{array}{c}\Psi \\
(\mathrm{deg})\end{array}$ & -12.832 & $1.62 \mathrm{E}-05$ \\
\hline$R(\mathrm{~m})$ & 1.672 & $2.72 \mathrm{E}-05$ & $k$ & 0.719 & $2.04 \mathrm{E}-07$ \\
\hline & & & $\begin{array}{c}R_{0} \\
(\mathrm{~m})\end{array}$ & 1.824 & $1.93 \mathrm{E}-07$ \\
\hline
\end{tabular}

Table 2. Estimated parameters of Part 2

\begin{tabular}{|c|c|c|c|c|c|}
\hline Part2 & $\begin{array}{c}\text { Estimated } \\
\text { Value }\end{array}$ & $\begin{array}{c}\text { Standard } \\
\text { deviation }\end{array}$ & $\begin{array}{c}\text { Estimated } \\
\text { Value }\end{array}$ & $\begin{array}{c}\text { Standard } \\
\text { deviation }\end{array}$ \\
\hline$X_{c}(\mathrm{~m})$ & -0.286 & $1.72 \mathrm{E}-03$ & $X_{c}(\mathrm{~m})$ & -0.099 & $1.99 \mathrm{E}-06$ \\
\hline$Y_{c}(\mathrm{~m})$ & 0.351 & $1.74 \mathrm{E}-03$ & $Y_{c}(\mathrm{~m})$ & -0.006 & $1.91 \mathrm{E}-06$ \\
\hline $\begin{array}{c}\Omega \\
(\mathrm{deg})\end{array}$ & -3.328 & $1.38 \mathrm{E}-02$ & $\begin{array}{c}\Omega \\
(\mathrm{deg})\end{array}$ & -0.552 & $3.57 \mathrm{E}-05$ \\
\hline $\begin{array}{c}\Phi \\
(\mathrm{deg})\end{array}$ & -3.947 & $1.38 \mathrm{E}-02$ & $\begin{array}{c}\Phi \\
(\mathrm{deg})\end{array}$ & -2.683 & $3.67 \mathrm{E}-05$ \\
\hline$k$ & 2.483 & $1.93 \mathrm{E}-03$ & $\begin{array}{c}\Psi \\
(\mathrm{deg})\end{array}$ & -12.839 & $2.81 \mathrm{E}-05$ \\
\hline$r(\mathrm{~m})$ & 2.817 & $5.50 \mathrm{E}-04$ & $k$ & 1.237 & $5.54 \mathrm{E}-06$ \\
\hline & & & $r(\mathrm{~m})$ & 3.159 & $5.36 \mathrm{E}-07$ \\
\hline
\end{tabular}

Table 3. Estimated parameters of Part 3

\begin{tabular}{|c|c|c|c|c|c|}
\hline & $\begin{array}{c}\text { Estimated } \\
\text { Value }\end{array}$ & $\begin{array}{c}\text { Standard } \\
\text { Deviation }\end{array}$ & $\begin{array}{c}\text { Estimated } \\
\text { Value }\end{array}$ & $\begin{array}{c}\text { Standard } \\
\text { Deviation }\end{array}$ \\
\hline$X_{c}(\mathrm{~m})$ & 0.003 & $1.02 \mathrm{E}-04$ & $X_{c}(\mathrm{~m})$ & 0.0002 & $2.55 \mathrm{E}-07$ \\
\hline$Y_{c}(\mathrm{~m})$ & -0.019 & $1.03 \mathrm{E}-04$ & $Y_{c}(\mathrm{~m})$ & -0.018 & $2.57 \mathrm{E}-07$ \\
\hline $\begin{array}{c}\Omega \\
(\mathrm{deg})\end{array}$ & 0.222 & $8.60 \mathrm{E}-03$ & $\begin{array}{c}\Omega \\
(\mathrm{deg})\end{array}$ & 0.241 & $2.15 \mathrm{E}-05$ \\
\hline $\begin{array}{c}\Phi \\
(\mathrm{deg})\end{array}$ & -1.506 & $8.49 \mathrm{E}-03$ & $\begin{array}{c}\Phi \\
(\mathrm{deg})\end{array}$ & -1.424 & $2.12 \mathrm{E}-05$ \\
\hline$R(\mathrm{~m})$ & 2.426 & $7.25 \mathrm{E}-05$ & $\begin{array}{c}\Psi \\
(\mathrm{deg})\end{array}$ & -12.863 & $1.32 \mathrm{E}-05$ \\
\hline & & & $\begin{array}{c}R_{0} \\
(\mathrm{~m})\end{array}$ & 2.653 & $2.09 \mathrm{E}-07$ \\
\hline
\end{tabular}

\subsection{Central Axis Estimation}

Nonetheless, fitting different parts of the pagoda to individual model independently will produce different central axes which are not collinear. Therefore, we propose different parts of the pagoda should be fitted to a set of corresponding geometric models simultaneously (Equation 7) to obtain a central axis whose estimation was contributed by all different parts of the pagoda under a single least-squares adjustment. The estimated parameters and their standard deviations are shown in Table 4. The central axis parameters (Xc, Yc, $\Omega, \Phi)$ are visualized by simulating a straight line (red) plotted along with the pagoda in Figures 9 and 10. The blue lines are the central axes of the individual parts obtained from independently hexagonal model fittings. It can be seen in Figure 10 (top view) that the blue axes are not collinear, and the red axis is located closer to the centre of the pagoda compared to the blue axes.

Table 4. Estimated parameters of the full pagoda

\begin{tabular}{|c|c|c|}
\hline & Estimated Value & Standard Deviation \\
\hline$X c(\mathrm{~m})$ & $4.903 \mathrm{E}-02$ & $3.483 \mathrm{E}-04$ \\
\hline$Y c(\mathrm{~m})$ & $-1.509 \mathrm{E}-02$ & $3.506 \mathrm{E}-04$ \\
\hline$\Omega(\mathrm{deg})$ & $9.717 \mathrm{E}-02$ & $4.458 \mathrm{E}-03$ \\
\hline$\Phi(\mathrm{deg})$ & $-1.901 \mathrm{E}+00$ & $4.435 \mathrm{E}-03$ \\
\hline$\Psi(\mathrm{deg})$ & $-1.280 \mathrm{E}+01$ & $1.724 \mathrm{E}-02$ \\
\hline$k_{1}$ & $7.214 \mathrm{E}-01$ & $6.569 \mathrm{E}-04$ \\
\hline$R_{I}(\mathrm{~m})$ & $5.474 \mathrm{E}+00$ & $3.324 \mathrm{E}-03$ \\
\hline$k_{2}$ & $1.216 \mathrm{E}+00$ & $1.489 \mathrm{E}-02$ \\
\hline$R_{2}(\mathrm{~m})$ & $7.374 \mathrm{E}+00$ & $4.989 \mathrm{E}-02$ \\
\hline$R_{3}(\mathrm{~m})$ & $2.653 \mathrm{E}+00$ & $5.324 \mathrm{E}-04$ \\
\hline$k_{4}$ & $1.667 \mathrm{E}+00$ & $2.059 \mathrm{E}-02$ \\
\hline$R_{4}(\mathrm{~m})$ & $2.679 \mathrm{E}+00$ & $8.519 \mathrm{E}-03$ \\
\hline$R_{5}(\mathrm{~m})$ & $2.768 \mathrm{E}+00$ & $5.366 \mathrm{E}-04$ \\
\hline$k_{6}$ & $1.608 \mathrm{E}+00$ & $2.645 \mathrm{E}-02$ \\
\hline$R_{6}(\mathrm{~m})$ & $-3.840 \mathrm{E}+00$ & $1.195 \mathrm{E}-01$ \\
\hline$R_{7}(\mathrm{~m})$ & $2.878 \mathrm{E}+00$ & $5.291 \mathrm{E}-04$ \\
\hline
\end{tabular}

On the other hand, the precisions of central axis parameters fall into reasonable ranges, given that the precision of the observations for the $\mathrm{X}, \mathrm{Y}$ and $\mathrm{Z}$ were set to $5 \mathrm{~cm}$. 


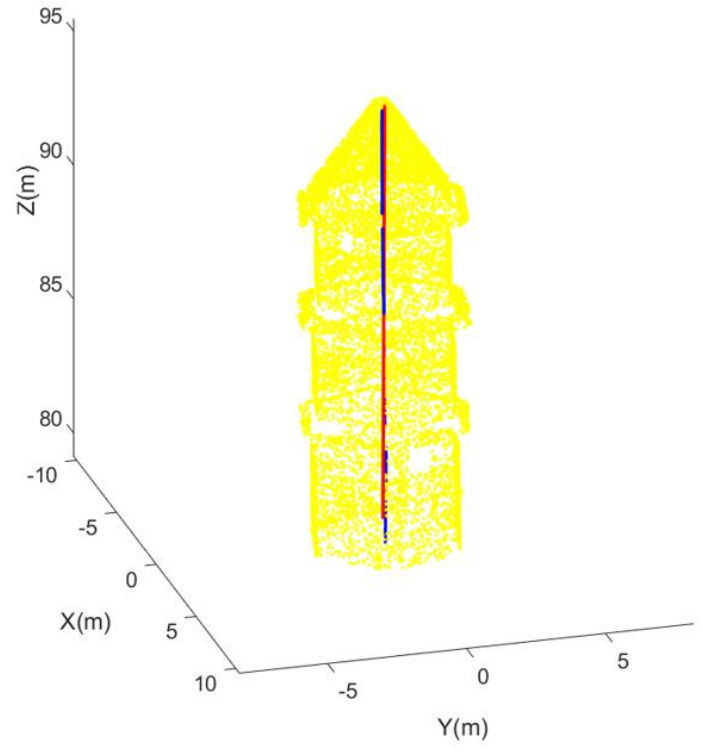

Figure 9. Side-view of the simulated axes obtained from the estimated parameters. Red: central axis obtained from the proposed model; Blue: central axes obtained from individual

hexagonal models; Yellow: the pagoda point cloud

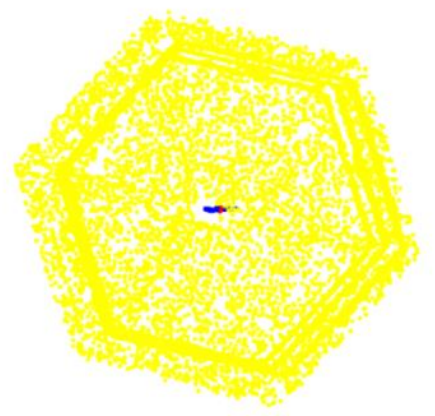

Figure 10. Top-view of the simulated axes obtained from the estimated parameters. Red: central axis obtained from the proposed model; Blue: central axes obtained from individual

hexagonal models; Yellow: the pagoda point cloud

The $q$ number is a by-product of the estimations. Correct distribution of the sextant number indicates the fitting and the model are appropriate (Chan et al., 2016).

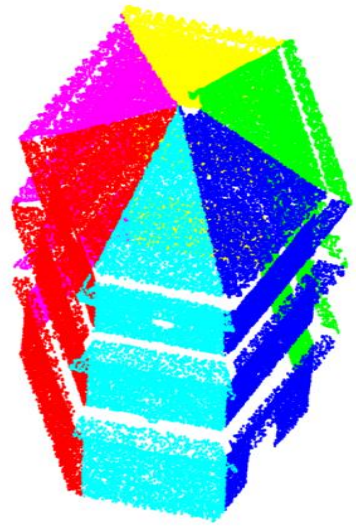

Figure 11. Sextant number obtained from the estimation. Red: $q$ $=1$; Cyan: $q=2$; Blue: $q=3$; Green: $q=4$; Yellow: $q=5$; Magenta: $q=6$
As seen in Figure 11, the sextant number are evenly distributed for each corresponding sector. Overall, the estimated parameters are in realistic ranges. Furthermore, the visualization of the central axis and the sextant number are proper, so the proposed estimation can be readily processed to analyse its symmetry. This is further confirmed with Figure 10 that all points in other sextants rotated to the first sextant (except those points belong to the first sextant) using the model parameters overlap each other appropriately.

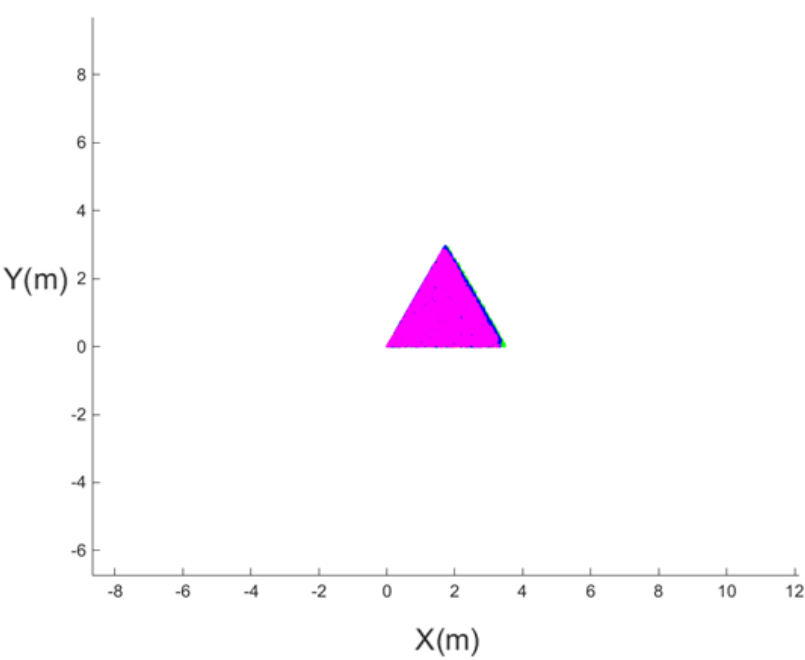

Figure 12. Points from different sextant number rotated to the first sextant (except points with $\mathrm{q}=1$ do not rotate) based on the model and the estimated parameter. Red: $q=1$; Cyan: $q=2$;

Blue: $q=3$; Green: $q=4$; Yellow: $q=5$; Magenta: $q=6$

Based on the result analysis, we can see that the proposed model consists of multiple prism and pyramid models implemented using a single adjust process fits well to the entire pagoda point clouds, yielding accurate parameters with high precision. This novel model allows all the observed points from pagodas with multiple floors with different dimensions and shapes can be used to input to the adjustment simultaneously to estimate a common central axis. The central axis was accurately estimated, and it can be used for successive symmetry analysis.

\section{CONCLUSION}

In this paper, we specifically investigate the structure and geometric modelling of a typical ancient Chinese pagodas which are usually polygonal architecture. We proposed a method invoking a novel geometric model which is comprised of multiple polygonal prism and pyramid models. The model can be incorporated into a single least-squares adjustment to estimate a unique central axis whose estimation is contributed by different parts of the pagodas simultaneously under the criteria that each part response to its own geometric model accordingly. A typical 300 years old Chinese pagoda having three floors was reconstructed using the UAV photogrammetry. The resultant point cloud was used to verify the proposed model. The estimated parameters are in realistic ranges. Also, the reconstructed central axis and the sextant number are well visualized, so the symmetry of the pagodas can be readily analysed to support various studies related to structural health monitoring or cultural heritage documentation. 


\section{ACKNOWLEDGEMENTS}

This work is supported by the Fundamental Research Funds for the Central Universities (Grant No. 37000-31610444), awarded to the first author. All authors are grateful for the support from Ministry of Housing and Urban-Rural Development; Ministry of Housing and Urban-Rural Construction Office in the research project of Examination and Evaluation of Historical Towns and Villages.

\section{REFERENCES}

Bartalucci, C., Furferi, R., Governi, L., and Volpe., Y., 2018. A survey of methods for symmetry detection on 3D high point density models in biomedicine, Symmetry 10(7), DOI: $10.3390 /$ sym 10070263

Berner, A., Bokeloh, M., Wand, M., Schilling A., and Seidel H., 2009. Generalized intrinsic symmetry detection' (MPI-I-20094-005). Saarbrücken: Max-Planck-Institut für Informatik.

Chan, T.O., and Lichti, D.D., 2014. Geometric modelling of octagonal lamp poles. International Archives of Photogrammetry, Remote Sensing and Spatial Information Sciences XL-5, 45150.

Chan T. O., Lichti, D.D., and Belton, D., 2015. A rigorous cylinder-based self-calibration approach for terrestrial laser scanners. ISPRS Journal of Photogrammetry and Remote Sensing 99, 84-99.

Chan, T. O., Lichti, D. D., Belton, D. and Nguyen, H. L., 2016. Automatic point cloud registration using a single octagonal lamp pole. Photogrammetric Engineering \& Remote Sensing, 82 (4), p. 257-269.

Cheng, L., Wu, Y., Chen, S., Zong, W., Yuan, Y., Sun, Y., and Zhuang, Q., Li, M., 2018. A symmetry-based method for LiDAR point registration. IEEE Journal of Selected Topics in Applied Earth Observations and Remote Sensing, 11(1), 285299.

Combès, B., Hennessy, R., Waddington, J., Roberts, N., and Prima, S., 2008. Automatic symmetry plane estimation of bilateral objects in point clouds. In Proceedings of the International Conference on Computer Vision and Pattern Recognition, Anchorage, ANC, USA.

Demantké J., Mallet C., David N. and Vallet B., 2011. Dimensionality based scale selection in 3D LiDAR point cloud. International Archives of Photogrammetry, Remote Sensing and Spatial Information Sciences 37 (5/W12), 97-102.

Förstner, W., and Wrobel, B., 2004. Mathematical concepts in photogrammetry, In: McGlone, J.C., Mikhail, E.M., Bethel, J., Mullen, R. (Eds.), Manual of Photogrammetry, fifth ed. American Society of Photogrammetry and Remote Sensing, Bethesda, MA, pp. 15-180.

Jiang, W., Xu, K., Cheng, Z, and Zhang H., 2013. Skeletonbased intrinsic symmetry detection on point clouds. Graphical Models, 75(4), 177-188.

Li, H., Zhu, Q., Huang, M., Guo, Y., and Qin, J., 2018. Pose estimation of sweet pepper through symmetry axis detection. Sensors, 18(9):3083.
Luo, D. and Wang, Y., 2008. Rapid extracting pillars by slicing point clouds. International Archives of Photogrammetry, Remote Sensing and Spatial Information Sciences, 37 (Part B3), pp. 215-218

Musuvathy, S., Cohen, E., and Damon, J., 2011. Computing medial axes of generic 3D regions bounded by B-spline surfaces. Computer-Aided Design, 43(11), 1485-1495.

Xue, F., Chen, K., and Lu, W., 2018 Architectural symmetry detection from 3D urban point clouds: A derivative-free optimization (DFO) approach. In Advances in Informatics and Computing in Civil and Construction Engineering (pp. 513519). Springer, Cham. 